\title{
XX. On some meteorological phænomena observed in the mount's bay, Cornwall
}

\author{
W.J. Henwood F.G.S. Hon. M.Y.P.S.
}

To cite this article: W.J. Henwood F.G.S. Hon. M.Y.P.S. (1834) XX. On some meteorological phænomena observed in the mount's bay, Cornwall , Philosophical Magazine Series 3, 4:20, 103-104, DOI: $10.1080 / 14786443408648270$

To link to this article: http://dx.doi.org/10.1080/14786443408648270

册 Published online: 01 Jun 2009.

Submit your article to this journal ¿

Џ Article views: 2

Q View related articles $₫$ 
Mr. Henwood on certain Meteorological Phcenomena. 103

modified in the details, has been lately recommended to the notice of the medical profession by Mr. Laming. In the original process a small portion of bitartrate of potash always remained in solution, so that the acid was always distilled when required for chemical use. The alcohol employed by $\mathrm{Mr}$. Laming to precipitate the bitartrate of potash renders the acid even more unfit for chemical purposes, although it is highly useful to add a small portion in the preparation of the medicinal acid.

However, pure hydrocyanic acid may be obtained at once by the decomposition of a solution of the cyanuret of calcium by oxalic acid. Heat is developed during the decomposition. The oxalate of lime is completely precipitated in a few hours, leaving the supernatant acid quite pure; but if slight traces of oxalate of lime are held in suspension, one filtration is sufficient, whilst in the process of Proust two filtrations are required. The liquid is quite pure, as the oxalate of lime is insoluble in hydrocyanic acid. In this process, as well as in Mr. Clarke's, the use of a mineral acid is avoided. The chief objection to its adoption for the preparation of hydrocyanic acid for chemical purposes, is the difficulty of procuring the cyanuret of calcium; but it is probable that an easy mode of obtaining that cyanuret will soon be discovered. The proportions required are one equivalent of oxalic acid and one equivalent of the cyanuret of calcium.

XX. On some Meteorological Phanomena observed in the Mount's Bay, Cornwall. By W. J. Henwood, F.G.S. Lond. and Paris, Hon. M.Y.P.S.

To the Editors of the Philosophical Magazine and Journal. Gentlemen,

$\mathrm{O}^{\mathrm{N}}$ the 18 th of November, at about $4^{\mathrm{h}}$ P.M., as I was walking on the beach between Penzance and Newlyn, my attention was drawn to a very dense black cloud $(a)$ hanging over the plateau of Paul Hill $(b)$. Towards the sea it shaded off, and immediately over the beach in that direction it terminated, a few small clouds appearing at intervals in the otherwise clear sky.

On continuing to observe it for some time, I found that although the mass of cloud was in motion before a somewhat brisk breeze from the south-east, yet, as one portion receded, another in taking its place became equally dark.

In fact, as successive portions of air, which, whilst over the sea, were transparent, approached the land, small light spots of cloud began to be formed; and when the same mass of air 
104 Dr. Ritchie on the Detonation of Oxygen and Hydrogen.

was brought over the land, these light clouds thickened, and united into one dense and dark one.

In company with Mr. John Phillips, I noticed this for about half an hour, and so far as we could judge, it continued after evening fall. On the following day both Mr. H. Thomas, to whom I am indebted for the accompanying sketch, and myself observed similar appearances on the same spot, which forms the western boundary of the bay, and over the Lizard Point $(c)$, which terminates it on the east.

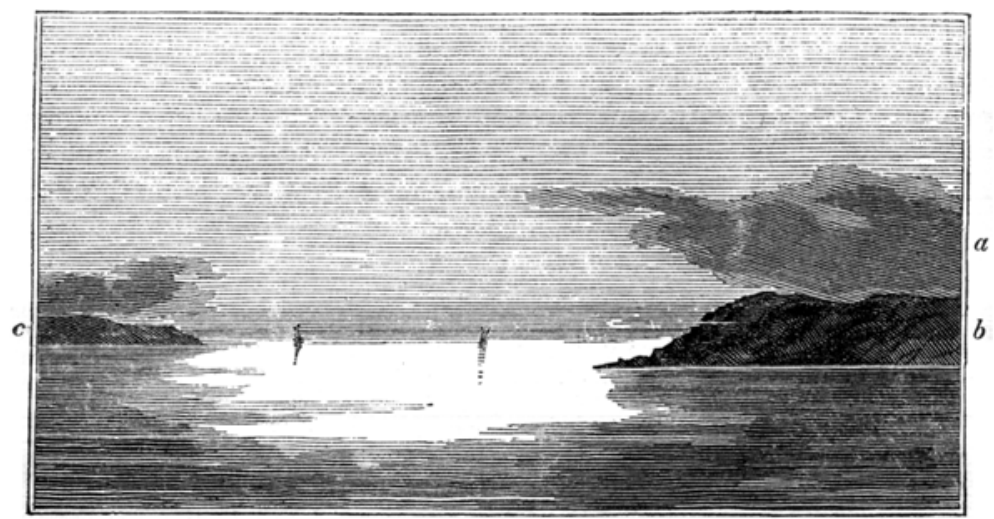

I have several times subsequently observed the like.

Mr. Harvey * has described similar phænomena occurring in the neighbourhood of Plymouth : in this part of the country I believe they are by no means unfrequent.

I have the honour to remain, \&c.

Geological Society, Penzance,

W.J. Henwood.

Dec. $4,1833$.

XXI. On the Mode of detonating a Mixture of Oxygen and Hydrogen by a Spark induced by a small horse shoe Magnet. By the Rev. Wiliani Ritchie, LL.D., F.R.S., \&c. Professor of Natural and Experimental Philosophy in the Royal Institution of Great Britain, and in the University of London.

To the Editors of the Philosophical Magazine and Journal.

Gentlemen,

IN a paper read before the Royal Society nearly two years ago, I first described the method of obtaining a spark from a small magnet sufficient to detonate a mixture of oxygen and

- Edinburgh Journal of Science, Jan. 1829, First Series, vol. x. p. 148. 